\title{
Economic event conceptualization through script theory
}

\author{
L. Harutyunyan
}

Armenian State University of Economics, Armenia, Yerevan

Corresponding author. E-mail: 1harutyunyan77@yahoo.com

Paper received 17.09.18; Accepted for publication 25.09.18.

\section{https://doi.org/10.31174/SEND-Ph2018-182VI53-02}

\begin{abstract}
Modern media make an inextricable part of human life and provide an essential way of learning about worldwide events. All means target the mass audience by letting them have access to information, and securing its dissemination. The media can thus exert a powerful influence on people's opinions by attracting their attention to certain events through the use of framing theory principles. Framing theory implies the presentation of the news to the audience in such a way that it impacts people's choices in perceiving and processing information. Frames are data-structures that work to organize message meaning. To understand events and situations, people use various frames or scripts that are registered in their memory in an orderly manner. There is a limited study done in regard to the field of economic events conceptualization from the view of cognitive linguistics. Therefore, the present paper attempts to make a modest contribution in this domain with analysis and discussion of the script and its constituents inherent in an economic event published on the website www.theguardian.com in 2014. It mainly addresses issues related to reading and understanding of business news, focusing on the organization and interpretation of scripts relevant to economic events. It discusses various theories concerning the nature and principles of economic events comprehension and the peculiarities regarding the structure of frames and scripts that are employed by people for processing information related to economic events. In the paper the theory of scripts is interpreted as a main tool for news message presentation on behalf of the journalist. As is known, scripts as types of a concept contain structural elements - terminals or slots that must be filled by specific instances or data (agent, change, time, location, recipient, intention, cause, result, etc.) which are activated in accordance with the provided information. These slots can be represented either explicitly or implicitly, depending on a variety of factors. We distinguish between nuclear and alternative parts inherent in the structure of scripts. Due to the nuclear part (agent, change, time, location), we are able to recognize the situation in the process of its interpretation, whereas the alternative part (recipient, intention, cause, result, forecast, evaluation, etc.) conveys conventional information about the latter. However, in the process of economic event conceptualization, they come forward and become salient to ensure the reader's comprehensive frame-building process.
\end{abstract}

Keywords: Economic Events, Business News, Framing Theory, Economic Event Conceptualization, Scripts for Economic Events Conceptualization.

It is now common knowledge that there are rules that people apply to understand various actions, situations and events that take place in our life. This theory was first put forth by Goffman who stated that people interpret what is going on around their world through their primary framework [6]. This framework is regarded as primary as it is taken for granted by the user. Goffman states that there are two distinctions within primary frameworks, namely natural and social. Both help people interpret data so that their experiences can be understood in a wider social context. The difference between the two is functional. Natural frameworks identify events as physical occurrences taking natural quote literally and not attributing any social forces to the causation of events. Social frameworks view events as socially driven occurrences, due to the whims, goals, and manipulations on the part of other social players (people). Social frameworks are built on the natural frameworks. These frameworks and the frames that they create in our communication greatly influence how data is interpreted, processed, and communicated. Goffman's underlying assumption is that individuals are capable users of these frameworks on a day to day basis whether they are aware of them or not.

Minsky is considered to be the founder of the frame theory in the domain of Artificial Intelligence. He defines a frame as 'a data-structure for representing a stereotyped situation like being in a certain kind of living room or going to a child's birthday party. There are several kinds of information attached to each frame. Some of this information is about how to use the frame. Some is about what one can expect to happen next. Some is about what to do if these expectations are not confirmed' [8]. Minsky's frame theory states that each situation is represented via a system of frames, each of which covering information about the possible perspectives of the situation. Various frames of the system show various ways of using information. Facing any situation, a person opts for an appropriate frame to understand it. This choice, in essence, is a choice of questions which should be posed for the situation in question.

Other proponents of situation and event comprehension theory, Shank and Abelson propose a structure labeled as a script and define it as a structured object representing a standardized generalized episode. The authors state that scripts are groups of causal chains that represent knowledge about frequently experienced events (e.g. going to a restaurant). In essence, a script is a stereotyped sequence of actions that defines a well-known situation and has associated with it

- a number of roles for the actors (different points of view on the situation, e.g. customer vs. waiter vs. cook),

- different tracks (e.g. restaurant, fast-food),

- different scenes (e.g. enter, order, eat, pay); each scene has a MAINCON, i.e. a main conceptualization, which must have happened if the scene is instantiated,

- as well as props, entry conditions, results, branches and loops etc.

The use of these scripts requires two mechanisms.

- Script retrieval: A script is retrieved if a state is mentioned that constitutes a precondition for the script (e.g. the customer is hungry and has money) and there is a direct reference to a MAINCON or a prop in one of the scenes (e.g. order a dish or step to the counter).

Script application: An active script allows one to infer actions that were not stated (nor contradicted) as well as to instantiate roles, etc [11]. 
Fillmore and Baker use the term frame in the context of linguistic analysis and offer a model for representing frame-based analysis of lexical meanings. Namely, the authors identify the following stages for understanding situations and events described via linguistic units:

1. Characterizing the frames, i.e., the situation types for which the language has provided special expressive means.

2. Describing and naming the frame elements, i.e., the aspects and components of individual frames that are likely to be mentioned in the phrases and sentences that are instances of those frames.

3. Selecting lexical units that belong to the frames, i.e., words from all parts of speech that evoke and depend on the conceptual backgrounds associated with the individual frames.

4. Creating annotations of sentences sampled from a very large corpus showing the ways in which individual lexical units in the frame allow frame-relevant information to be linguistically presented.

5. Automatically generating lexical entries, and the valence descriptions contained in them that summarize observations derivable from them.

Overall, this kind of semantic analysis involves characterizing the situation types evoked by (classes of) lexical units, determining the kinds of participant roles (frame elements) required to complete the details of instances of any such frame, and discovering and documenting the ways in which such elements are syntactically realized[6].

All these approaches and terms are closely related to the theory of framing and media discourse understanding, the process in which journalists decide which of their readers' frames to activate and incorporate in the whole frame-building process. According to Kuypers, 'Framing is a process whereby communicators, consciously or unconsciously, act to construct a point of view that encourages the facts of a given situation to be interpreted by others in a particular manner. Frames operate in four key ways: they define problems, diagnose causes, make moral judgments, and suggest remedies. Frames are often found within a narrative account of an issue or event, and are generally the central organizing idea.' [7]. The theory of framing is widely used in political discourse organization where it is viewed as 'the process by which a communication source, such as a news organization, defines and constructs a political issue or public controversy [9, p.221]. However, we build on the hypothesis that it could be also applied to economic event interpretation and comprehension in media discourse. Framing theory, as well as the analysis of the constituents of economic events scripts and lexical means representing them may be relevant to the comprehension of discourse media messages.

An economic event may be defined as any occurrence that takes place in the global economy as well as in certain countries' economies, which involves any situation triggering ups and downs of economy and is evaluated by society as a vital and significant change in the economic world. For instance, the production of new items/services, the launch of companies, the start of their cooperation, mergers, takeovers, collapses, a sudden fall or increase in the value of securities/shares, sanction imposition on countries and so on can be considered as significant events happening in the business world. For example:
The collapse of Lehman Brothers, a sprawling global bank, in September 2008 almost brought down the world's financial system [2]. (collapse)

Apple launched its new music-streaming service, which is based on the one that was offered by Beats Electronics before Apple bought the firm last year [1]. (the production of a new service)

President Vladimir Putin signed a decree imposing a raft of punitive economic sanctions against Turkey on Saturday underlining the depth of the Kremlin's anger toward Ankara four days after Turkey shot down a Russian warplane [10]. (sanction imposition)

Thus, all these occurrences can be perceived as economic events that happen in the business world on a day to day basis.

The analysis of factual material shows that the interpretation of any economic event highlighted in media discourse implies identifying the script which consists of nuclear and alternative parts. The nuclear part involves such slots as the agent, the change, the location and the time. At the same time, such slots as recipient, cause, result, intention, forecasts about further development of events, their evaluation by a reader etc., play a secondary role in the procedure of understanding the situation and constitute the alternative part of the script. The absence of this information does not prevent a reader from perceiving a certain situation. When needed, they come forward and become salient enabling the reader to gain insight into the plot of the event.

This is provided by a specific text structure of business news which is organized in a completely different manner. In comparison with argumentatively structured discourse, such as scholarly papers, where the important conclusion comes at the end, news in the daily press, as van Dijk states, is organized by the principle of relevance or importance, along a dimension of decreasing prominence with respect to the macrostructure. This means that one can read only the headlines or the lead, or only some part of the discourse, and still process the most important information. They organize attention for specific articles, allowing one to decide whether or not to read the rest of the discourse and giving the main theme, even without further reading. Finally, they activate the relevant knowledge from memory that is needed in order to understand the rest of the text and form a macrostructure that will serve as an important strategic cue in controlling the local understanding of the subsequent text [3, p. 35].

Let us analyze an economic event published on www.theguardian.com in 2014 to observe how this specific news text structure and the aforementioned slots are reflected and interact with each other to create an overall picture of this economic event script. The choice of the discussed article is conditioned by the fact that here all the slots are vividly expressed to contribute to a comprehensible understanding of this economic event [4]. The analysis has come to prove that the slots of the nuclear part of the script that is to say the most important information relevant to this economic event are comprised in the headline of the article.

The headline of the article is "EU and US impose sweeping economic sanctions on Russia", where we can see the nuclear slot of the agent consisting of two parts (EU, USA), the slot of change (impose sweeping 
economic sanctions) and the alternative slot of the recipient (Russia), which, in this case, is activated and becomes salient to provide the reader with an access to further information. The journalist applies a well-known journalistic strategy by using the names of countries in the slot of the agent. Thus, avoiding mentioning the names of people who imposed sanctions, s/he generalizes the doers of the action (though later in the article we can already see their names - Barack Obama, Herman van Rompuy, José Manuel Barroso).

The tense (the Simple Present Tense) used in the slot of change shows that this event has already happened and in this context it is perceived negatively. As it is known, the Simple Present Tense is used when we talk about completed actions and events which are finished before the sentences that describe them [12].

The slot of time is mentioned implicitly, it is not mentioned in the text of the article, and we can see it on the website - 29.07. 2014. The same holds for the slot of the location, and the reader, taking into consideration the fact that this decision was made by the EU, understands that the event took place in Brussels.

European capital markets to be closed to Russian banks

Sanctions intended to stop supply of arms to Ukraine rebels

Downing St to push for harsher sanctions if no change

In the lead of the article two slots are represented those of intention (intended to stop supply of arms to Ukraine rebels) and forecast represented by two sentences:

1. European capital markets to be closed to Russian banks

2. Downing St to push for harsher sanctions if no change

At the beginning of the article the slot of the cause is also mentioned - in response to Moscow's continued backing for separatists in eastern Ukraine. Detailed information on the slot of the recipient (Russia) is also provided, that is the fields that are going to be targeted:

EU governments have agreed to impose sweeping sanctions on Russia, targeting state-owned banks, imposing an arms embargo and restricting sales of sensitive technology and the export of equipment for the country's oil industry, in response to Moscow's continued backing for separatists in eastern Ukraine.

Next we can also observe the evaluation slot. The journalist uses the superlative degree of the adjective extensive (the most extensive) and points out that the sanctions are the most extensive since the cold war and the ambassadors from the 28 member countries after a seven-hour debate gave their agreement concerning this issue. In such a way, the journalist tries to highlight the importance of the event.

The cause slot is also provided in detail, according to which Moscow did not meet certain conditions related to stopping the supply of arms to the rebels and providing full cooperation in the investigation into the shooting down of Malaysia Airlines flight MH17:

The punitive measures, the most extensive EU sanctions imposed on Russia since the cold war, were agreed by ambassadors from the 28 member states after a sevenhour debate. They decided that Moscow had not fulfilled the conditions laid down by foreign ministers last week, to stop the supply of arms to the rebels and provide full cooperation in the investigation into the shooting down of Malaysia Airlines flight MH17.

As we can see, the agent slot is presented by US president Barack Obama, who announced new measures, targeting major sectors of the Russian economy, which, in its turn, is considered to be the change slot:

US president Barack Obama joined the EU in sharply escalating economic pressure on Moscow. He announced new measures, targeting major sectors of the Russian economy, including weapons, energy and finance. Three large banks - VTB Bank OAO, Bank of Moscow and the Russian Agricultural Bank - were cut off from the US economy.

The slot of evaluation is completed by US president's cited words, according to which Russia is once again isolating itself from the international community, setting back decades of genuine progress. This message contributes to the addressee's evaluative disposition formation, evoking a negative attitude toward Russia:

"Today, Russia is once again isolating itself from the international community, setting back decades of genuine progress," the president said.

In general, the slot of evaluation is subjective by nature and significantly depends on both journalists' and readers' mentality, disposition and attitude towards the news. As van Dijk mentions 'It is now known more or less explicitly, in precise cognitive models, what it means to be 'biased,' what the relation is between textual structures and representations of 'reality,' what the precise conditions are of the well-known "selective perception" of both journalists and readers' [3, p. 29].

The evaluation of the discussed economic event is also performed by the cited words of the president of the European Council and the head of the European Commission. They accuse Russia of illegal annexation of the territory and deliberate destabilisation of Ukraine:

The president of the European Council, Herman van Rompuy, and the head of the European Commission, José Manuel Barroso, issued a joint statement describing the EU measures as a strong warning that "Illegal annexation of territory and deliberate destabilisation of a neighbouring sovereign country could not be accepted in 21 stcentury Europe.

In the message on the Malaysian plane, Herman van Rompuy and José Manuel Barroso apply parallel syntactic constructions (The European Union will fulfill its obligations to protect and ensure the security of its citizens. And the European Union will stand by its neighbours and partners.), which, in this case, underlines the depth of anger and resentment experienced by these people:

"When the violence created spirals out of control and leads to the killing of almost 300 innocent civilians in their flight from the Netherlands to Malaysia, the situation requires urgent and determined response," they said. "The European Union will fulfill its obligations to protect and ensure the security of its citizens. And the European Union will stand by its neighbours and partners."

The slot of forecast is also presented by the information according to which these sanctions are going to be the hardest for Russia: 
The EU sanctions will hit Russia the hardest. The bloc does 10 times more trade with it than the US.

Thus, in this economic event highlighting article both nuclear (agent, change, time, space) and alternative slots (recipient, cause, intention, evaluation and forecast) are present. It should be noted that the slots of recipient, cause and intention are activated and become salient to make the understanding of this event more comprehensible.

In the light of the results obtained in this paper, the following conclusions can be drawn:

The structural description of any economic event is fulfilled based on the information represented by frames. This type of information exists in the form of a script, which involves data about people and the goals of their activities. The script is a means of arranging information and representing it in the form of frames. Various lexical means presenting information about an economic event, chosen by a journalist in accordance with the principles of the theory of framing, play a primary role in providing clues to economic event conceptualization. Scripts are an extensive database based on cultural and social perceptions and values. As a type of a concept, a script contains structural elements - terminals or slots that must be filled by specific instances or data (agent, change, time, location, recipient, intention, cause, result, etc.) which are activated in a certain way in accordance with the information provided. The mentioned constituents can be represented either explicitly or implicitly, depending on a variety of factors. This fact enables us to distinguish nuclear and alternative parts inherent in the structure of scripts. Due to the nuclear part (agent, change, time, location), it is feasible to recognize the situation in the process of its interpretation, whereas the alternative part (recipient, intention, cause, result, forecast, evaluation, etc.) conveys conventional information about the latter. However, in the process of economic event conceptualization, they come forward and become salient to ensure the reader's comprehensive frame-building process. Through semantic analysis carried out by a person, it is possible to understand the message describing a situation or an event expressed via various linguistic means. In the interaction with the surrounding world, the script is adapted to the given economic event, as the information about the stereotyped situation is not always equivalent to the data about the objective reality. Through the processes of reading, analyzing, organizing a corresponding script with its inherent constituents or slots, retrieving information from memory, combining and adapting it with the present data, it is possible to comprehend the message about an economic event illustrated in the media discourse.

\section{REFERENCES}

1. Apple and the Music Business. The Second Revolution. The Economist.

URL:

https://www.economist.com/news/business-and-

finance/21653840-apple-which-has-already-transformedmusic-business-trying-do-so-again-second.

2. Crash Course. The Economist. URL: https://www.economist.com/news/schoolsbrief/21584534effects-financial-crisis-are-still-being-felt-five-years-article.

3. Dijk van T.A. (1983) Discourse Analysis: Its Development and Application to the Structure of News //Journal of Communication, Volume 33/2, pp. 20-43.

4. EU and US impose sweeping economic sanctions on Russia. The Guardian. URL: https://www.theguardian.com/world/2014/jul/29/economicsanctions-russia-eu-governments.

5. Fillmore Ch. J., Baker, C. (2009) A Frames Approach to semantic Analysis // The Oxford Handbook of Linguistic Analysis. Oxford University Press.

6. Goffman E. (1974) Frame Analysis: An Essay on the Organisation of Experience. N.Y.: Northeastern University Press.
7. Kuypers, J.A. (2006) Bush's War: Media Bias and Justifications for War in a Terrorist Age. Rowman \& Littlefield Publishers.

8. Minsky M. (1974). A Framework for Representing Knowledge. http://web.media.mit.edu/ minsky/papers/Frames/frames.htm

9. Nelson, T.E., Oxley, Z.M., Clawson, R.A. (1997) Toward a Psychology of Framing Effects // Political Behavior, 19, pp. 221-246.

10. Putin, citing national security, signs Turkey sanctions decree. Reuters. URL: http://www.reuters.com/article/us-mideastcrisis-turkey-russia-kremlin-idUSKBNOTH0H720151128.

11. Schank R.C., Abelson R.P. (1977) Scripts, Plans, Goals, and Understanding: An Inquiry into Human Knowledge Structures. Hillsdale, NJ: Lawrence Erlbaum.

12. Swan, M. (1995) Practical English Usage. Second Edition. Oxford University Press. 